Brit. Heart Y., 1969, 31, 184.

\title{
Influence of Electronically Paced Ventricular Rate on Urine Flow and Excretion of Minerals in Patients with Total Heart Block
}

\author{
E. DEKKER \\ From the University Department of Cardiology and Clinical Physiology, Wilhelmina-Gasthuis, \\ Amsterdam, The Netherlands
}

Patients with total heart block may present with congestive heart failure and considerable oedema which may be corrected by use of an electronic pacemaker (Müller and Bellet, 1961; DeSanctis, 1963; Schüller, Tryding, and Westling, 1964; Friedberg et al., 1965). These observations suggest some relation between paced rate and the renal excretion. of minerals and water.

In a preliminary study (Dekker et al., 1963) in a single patient with total heart block, renal excretion of sodium, water, and chloride was greater during an electronically induced heart rate of 100 a minute than at a rate of 50 a minute.

Recent studies seem to indicate, however, that in patients with total heart block the sodium excretion is decreased in response to an acute increase in heart rate (Humphries et al., 1967).

In this report the urine flow and renal excretion of minerals and water at different paced heart rates are therefore re-examined in some detail.

\section{SUBJECTS AND METHODS}

The studies were made in 5 patients with total heart block, suffering from frequent attacks of Adams-Stokes disease resistant to medical therapy. They were treated with an external pacemaker with an adjustable rate, connected either to an electrode catheter or to an implanted electrode. Table I gives some of the pertinent clinical data. All patients presented with idioventricular rhythm without oedema or pulmonary congestion. They were in bed in recumbent or semirecumbent position throughout the studies.

The patients were maintained on a constant diet consisting of biscuits, butter, sugar, milk, and water in

Received July 1, 1968. quantities adjusted to the individual calorie requirements in 6 equal portions per 24 hours, taken at the beginning of each 4-hour period, together with a capsule containing $14 \mathrm{mEq}$ sodium, $2.3 \mathrm{mEq}$ bicarbonate, and $12 \mathrm{mEq}$ chloride. At the end of each period the patient emptied his bladder. The urine flow was measured and the urine was analysed for sodium, potassium, and creatinine. The chloride excretion was measured in 3 patients.

The pacemaker rate was changed from 50 to 100 pulses a minute or in one patient from 40 to 80 pulses a minute and vice versa at the beginning of each successive 4-hour period. At 04.00 hours, however, this change was omitted, so that on successive days there was a different rate at the same hour. This experimental design served to compensate for the influence of the diurnal rhythm of water and electrolyte excretion on the total end results. The excretion data during different heart rates were thus obtained in a proper form for statistical analysis. The differences between the excretion values were statistically evaluated by means of the Wilcoxon test (Mann and Whitney, 1947).

At the end of the observation period in patients $B$ and $C$ the excretion of water and minerals was determined under the same regimen during a constant heart rate of 75 a minute for several days.

In patients $\mathbf{A}, \mathbf{B}$, and $\mathbf{C}$ the cardiac output was determined at various heart rates by means of right heart catheterization, using the Fick principle. Oxygen saturations were determined by the method of van Slyke. The oxygen consumption was measured after collection of the expired air in a Douglas bag by the method of Scholander (1947).

In urine analysis the following methods were employed: sodium and potassium were determined by flame photometry, chloride by a modification of the method of Votocek (Schales, 1953), and creatinine by the method of Jaffe in the modification of de Vries and van Daatselaar (Gorter and de Graaff, 1955). 
TABLE I

PERTINENT CLINICAL DATA

\begin{tabular}{|c|c|c|c|c|c|}
\hline Patient & Age (yr.) & Sex & $\begin{array}{l}\text { Duration of total } \\
\text { heart block (yr.) }\end{array}$ & $\begin{array}{l}\text { Idioventricular } \\
\text { rate }\end{array}$ & Symptoms \\
\hline A & 49 & $\mathbf{M}$ & $1 / 2$ & 28 & $\begin{array}{l}\text { Adams-Stokes attacks; extreme } \\
\text { fatigue, dyspnoea on exertion, } \\
\text { angina }\end{array}$ \\
\hline B & 35 & $\mathbf{M}$ & $2 \frac{1}{2}$ & 30 & Adams-Stokes attacks; nervous \\
\hline C & 75 & $\mathbf{M}$ & 1 & 32 & Adams-Stokes attacks, slight dys- \\
\hline $\mathbf{D}$ & 67 & $\mathbf{F}$ & $3 / 4$ & 36 & Adams-Stokes attacks, dyspnoea \\
\hline $\mathbf{E}$ & 72 & $\mathbf{M}$ & 5 & 32 & $\begin{array}{l}\text { Adams-Stokes attacks, slight dys- } \\
\text { pnoea on exertion }\end{array}$ \\
\hline
\end{tabular}

TABLE II

MEAN URINE VOLUME, CONCENTRATION, AND QUANTITY OF MINERALS AND CREATININE EXCRETED PER 4-HOUR PERIOD AT DIFFERENT HEART RATES

\begin{tabular}{|c|c|c|c|c|c|c|c|c|c|c|}
\hline Patient & $\begin{array}{c}\text { Heart rate/ } \\
\text { min. }\end{array}$ & $\begin{array}{c}\text { Urine } \\
\text { volume (ml.) }\end{array}$ & $\begin{array}{l}\text { Sodium } \\
\mathrm{mEq} / 1 .\end{array}$ & $\mathrm{mEq}$ & $\begin{array}{l}\text { Potassium } \\
\mathrm{mEq} / \mathrm{l} .\end{array}$ & $\mathbf{m E q}$ & $\begin{array}{l}\text { Chloride } \\
\mathrm{mEq} / 1 \text {. }\end{array}$ & $\mathrm{mEq}$ & $\begin{array}{c}\text { Creatinine } \\
\text { mg./l. }\end{array}$ & mg. \\
\hline $\mathbf{A}$ & $\begin{array}{r}50 \\
100\end{array}$ & $\begin{array}{l}202 \\
449^{\star}\end{array}$ & $\begin{array}{l}75 \\
93 \star\end{array}$ & $\begin{array}{l}14 \cdot 3 \\
40 \cdot 0^{\star}\end{array}$ & $\begin{array}{l}39 \\
25 \star\end{array}$ & $\begin{array}{c}7 \cdot 4 \\
10 \cdot 6 \star\end{array}$ & $\begin{array}{l}87 \\
89+\end{array}$ & $\begin{array}{l}16 \cdot 2 \\
37 \cdot 7^{\star}\end{array}$ & $\begin{array}{c}1043 \\
494^{\star}\end{array}$ & $\begin{array}{l}167 \\
189 \star\end{array}$ \\
\hline B & $\begin{array}{r}50 \\
100\end{array}$ & $\begin{array}{l}199 \\
316^{\star}\end{array}$ & $\begin{array}{l}71 \\
89 t\end{array}$ & $\begin{array}{l}13 \cdot 5 \\
26 \cdot 9 \star\end{array}$ & $\begin{array}{l}58 \\
42^{\star}\end{array}$ & $\begin{array}{l}10.5 \\
13 \cdot 7 t\end{array}$ & $\begin{array}{l}80 \\
89 t\end{array}$ & $\begin{array}{l}15 \cdot 2 \\
26 \cdot 8 \star\end{array}$ & $\begin{array}{l}1649 \\
1147^{\star}\end{array}$ & $\begin{array}{l}299 \\
308 t\end{array}$ \\
\hline C & $\begin{array}{r}50 \\
100\end{array}$ & $\begin{array}{l}120 \\
177^{\star}\end{array}$ & $\begin{array}{l}112 \\
126 t\end{array}$ & $\begin{array}{l}12 \cdot 4 \\
21 \cdot 5 \star\end{array}$ & $\begin{array}{l}66 \\
54 t\end{array}$ & $\begin{array}{l}7 \cdot 0 \\
9 \cdot 1^{\star}\end{array}$ & $\begin{array}{l}126 \\
132 t\end{array}$ & $\begin{array}{l}13 \cdot 8 \\
22 \cdot 3^{\star}\end{array}$ & $\begin{array}{l}1640 \\
1200^{\star}\end{array}$ & $\begin{array}{l}177 \\
198^{\star}\end{array}$ \\
\hline D & $\begin{array}{r}50 \\
100\end{array}$ & $\begin{array}{l}129 \\
321^{\star}\end{array}$ & $\begin{array}{l}44 \\
48+\end{array}$ & $\begin{array}{c}5 \cdot 5 \\
14 \cdot 6^{\star}\end{array}$ & $\begin{array}{l}31 \\
20 \star\end{array}$ & $\begin{array}{l}3 \cdot 8 \\
6 \cdot 1^{\star}\end{array}$ & - & - & $\begin{array}{l}808 \\
430 \star\end{array}$ & $\begin{array}{c}98 \\
131^{\star}\end{array}$ \\
\hline $\mathbf{E}$ & $\begin{array}{l}40 \\
80\end{array}$ & $\begin{array}{l}160 \\
498^{\star}\end{array}$ & $\begin{array}{l}44 \\
56 t\end{array}$ & $\begin{array}{c}7 \cdot 1 \\
28 \cdot 1^{\star}\end{array}$ & $\begin{array}{l}44 \\
24^{\star}\end{array}$ & $\begin{array}{c}6 \cdot 6 \\
11 \cdot 6^{\star}\end{array}$ & - & 二 & $\begin{array}{c}1254 \\
519 \star\end{array}$ & $\begin{array}{l}192 \\
251 t\end{array}$ \\
\hline
\end{tabular}

$\star \mathbf{p}<0.05$.

$+p>0.05$

\section{RESULTS}

The urine flow and excretion patterns in the 5 patients are shown in Fig. 1-5 and summarized in Table II.

Urine Flow. The mean urine flow was 48 to 211 per cent greater at the higher heart rate of 80 to 100 a minute than at rates of 40 to 50 a minute.

Sodium and Chloride. Sodium excretion during episodes with the higher heart rate exceeded those during the lower heart rate by 73 to 296 per cent. With the mineral load used in these experiments, the excretion of chloride ions was approximately equal to that of sodium ions in all periods. The urine concentrations of sodium and chloride were on the average slightly higher during the higher heart rates, though this difference reached a $p$ value of 0.05 for sodium in one patient only. The increased excretion of sodium and chloride during the higher heart rates seemed primarily determined by an increased urine flow.

Potassium. During the higher heart rates 30 to 76 per cent more potassium was excreted in the urine ( $p<0.05$ in 4 patients). It was, however, of a smaller magnitude than the corresponding differences in urine flow and sodium and chloride excretion at different heart rates. This was due to the fact that the urinary potassium concentration was 18 to 45 per cent lower at the higher heart rates.

Creatinine. The concentration of creatinine in the urine was lower in all patients at higher heart rates. The total amount of creatinine excreted per 4-hour period was slightly ( 3 to $34 \%$ ) higher at the higher heart rates, with a $p$ value $<0.05$ in 3 patients.

Cardiac Output Studies. The results of measurements of cardiac output during right heart catheterization are shown in Table III. In patient B there was a considerable increase in cardiac output with increasing heart rate. In patients $A$ and $C$ the increase was moderate as stroke volume varied inversely with heart rate.

Diurnal Rhythm. In some patients, when the heart was periodically switched between approxim- 


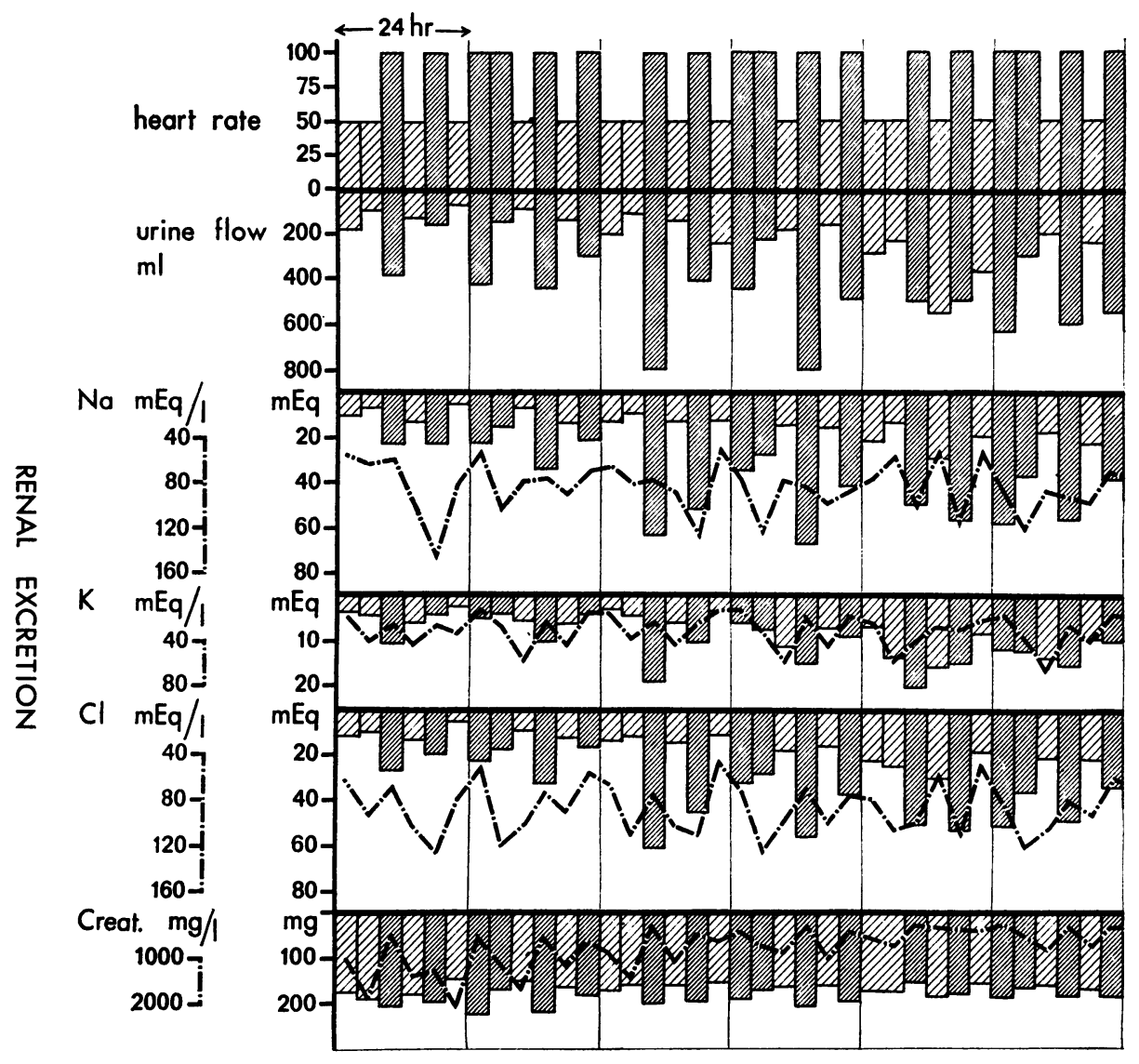

FIG. 1.-Heart rate, urine flow, and renal excretion of sodium, potassium, chloride, and creatinine in patient A. All excretion values are plotted downward. The columns represent heart rate and total quantities excreted per 4-hour period. The darker columns refer to the higher heart rate. The dotted lines show the concentrations of the respective solutes.

ately 50 and 100 a minute, the diurnal rhythm of renal excretion tended to be concealed. When the heart rate was held constant in patients $\mathrm{B}$ and $\mathrm{C}$ a clear diurnal rhythm could be observed (Fig. 2 and 3).

\section{DisCUSSION}

It is evident from these observations that paced heart rate has a profound influence on urine flow

TABLE III

CARDIAC OUTPUT (L./MIN.) AT DIFFERENT PACED HEART RATES

\begin{tabular}{c|c|c|c|c|c}
\hline \multirow{3}{*}{ Patient } & \multicolumn{5}{|c}{ Heart rate/min. } \\
\cline { 2 - 6 } & 50 & 75 & 100 & 125 & 135 \\
\hline A & 3.5 & 4.5 & $\overline{7}$ & $\overline{10.6}$ & 3.7 \\
B & 8.7 & 11.6 & 14.0 & 10.6 & $=$ \\
\hline
\end{tabular}

and mineral excretion in patients with total heart block.

Urine flow and total excretion of sodium and chloride were considerably greater at higher heart rates of 80 to 100 a minute when compared to lower rates of 40 to 50 a minute. This effect was acute: a four-hour period was adequate to bring it out. As no shorter collection periods have been used, no further statement can be made about the time interval between the change of rate and its renal effects within this four-hour period.

The observations in patients $B$ and $C$ showing a clear diurnal rhythm at a constant paced rate of $\mathbf{7 5}$ a minute are of some interest. A diurnal renal rhythm can evidently exist independent of diurnal variations in heart rate.

The interpretation of the excretion data on creatinine and potassium requires a somewhat elaborate discussion. 


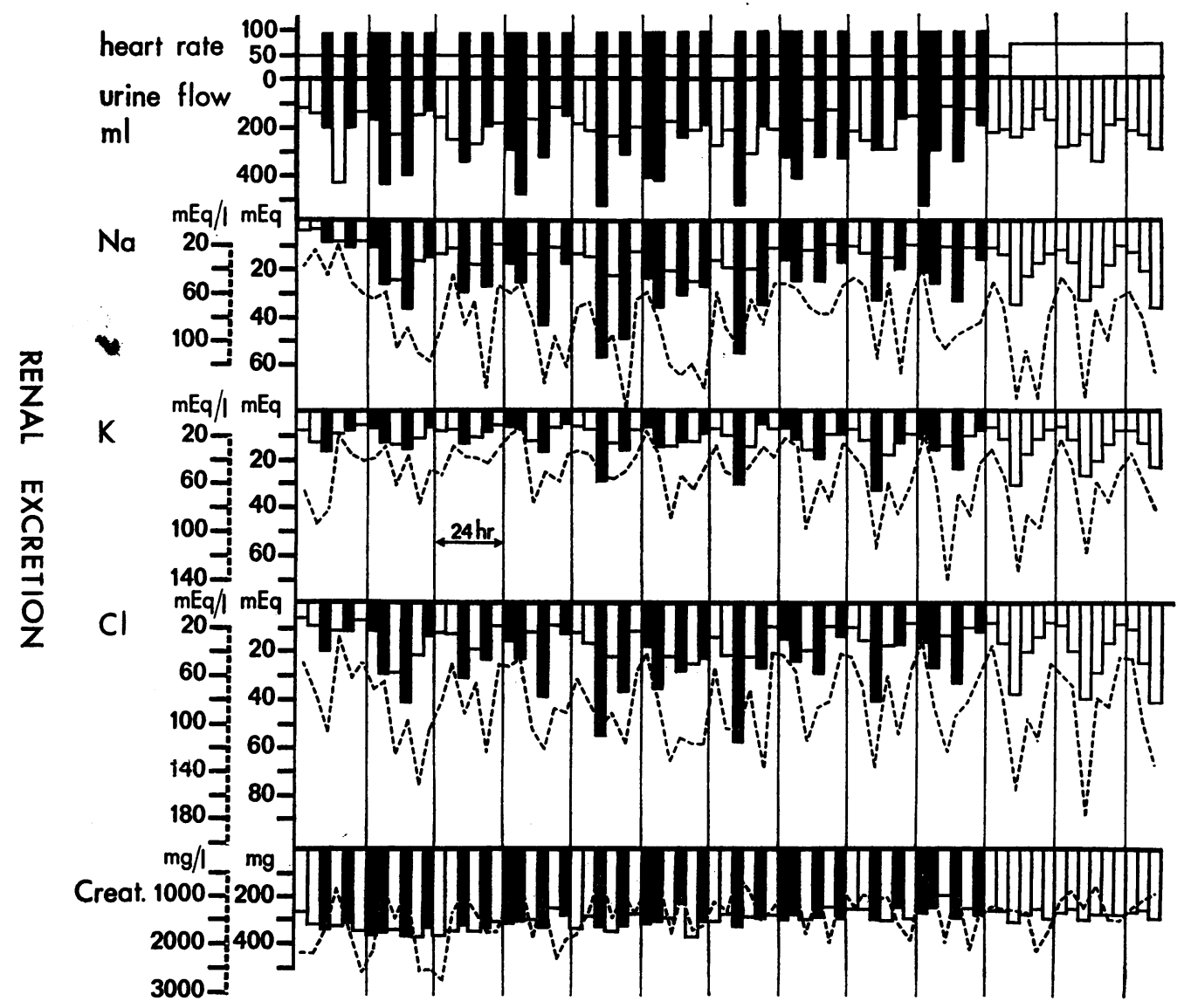

FIg. 2.-Heart rate and excretion data in patient B. (See legend to Fig. 1.) At a constant heart rate of 75 a minute the mineral excretion shows a diurnal rhythm.

In general, the interpretation of renal excretion data from urine samples in a non-steady state of renal function must take into account the "dead space" effect (Bojesen, 1954). This effect is especially bothersome when urine samples are small compared to the volume of the "dead space", i.e. part of the renal ducts, pyela, ureters, bladder, and urethra. This dead space volume will change under clinical conditions, causing a scatter in the results, which can be partly overcome by the statistical methods used in these studies, if it is assumed that urinary dead space is independent of heart rate.

Under conditions of constant dead space, any change in urine flow at the renal level is faithfully recorded in the collected urine sample. This is not necessarily so with concentrations and total amounts of a solute excreted. If the concentration of a solute changes at the kidney level at the beginning of a sampling period, some time will elapse before urine with the new concentration enters the sample. Thus, the product of concentration and volume of the voided urine no longer accurately reflects the total amount of solute excreted at the renal level during the sampling period. The results can be confusing.

Given a solute that is excreted by the kidney in a constant quantity per unit time, at different rates of urine flow the concentration of that solute will of course vary inversely with flow. Thus, under the conditions of these studies where urine flow switches from high to low values and vice versa, the kidney would excrete such a substance in alternating fractions of a high concentration at low flow and a low concentration at a large flow. At the transition from low to high urinary flow the dead space which contains a high concentration will be washed out rapidly and thoroughly. Conversely, at the transition from high to low urinary flow the dead space 


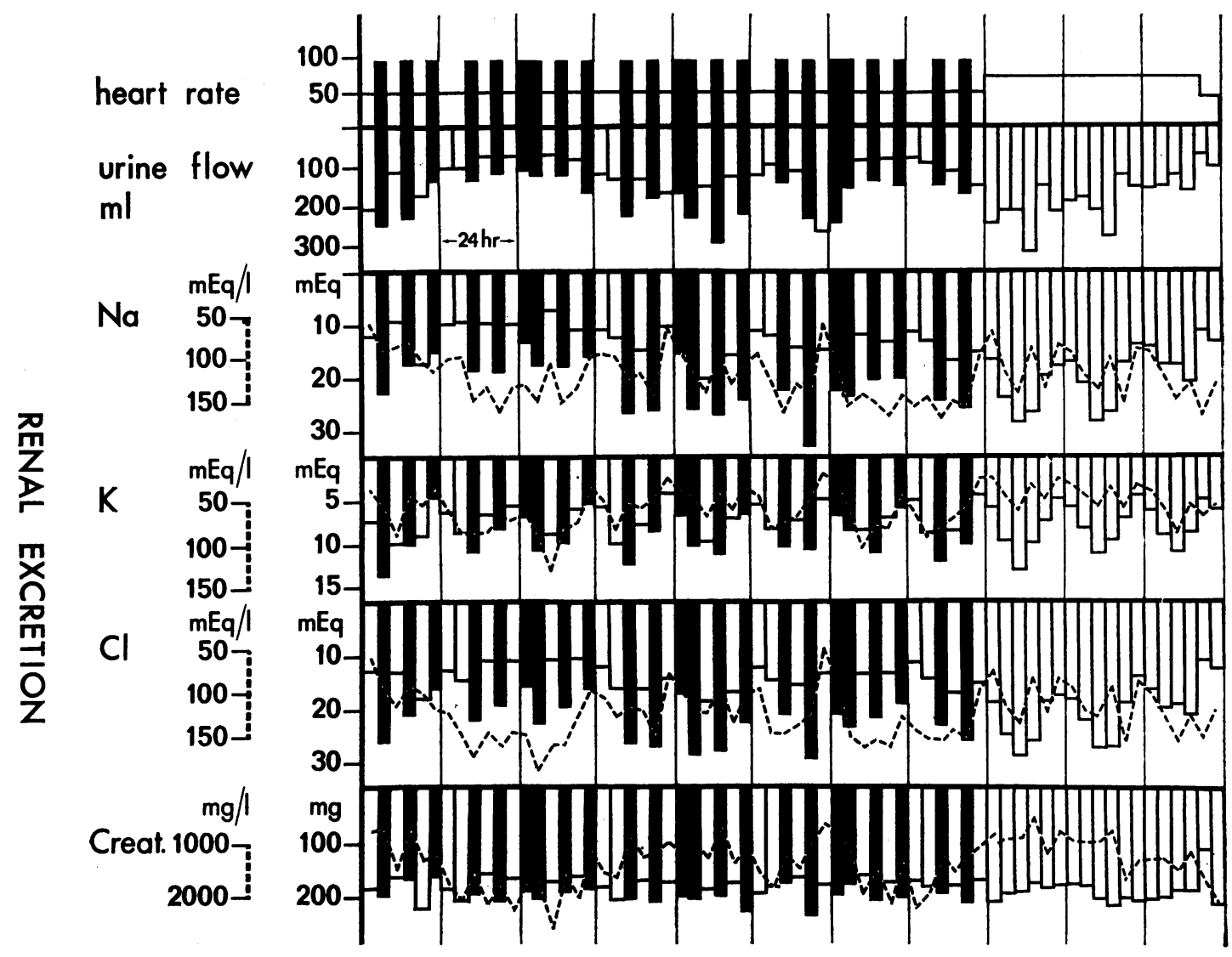

FIG. 3.- Heart rate and excretion data in patient C. (See legend to Fig. 1 and 2.)

containing a low concentration of the solute is slowly washed out. The net result is that a solute excreted by the kidney at a constant quantity per unit time, during alternating and equal periods of high and low flow, will appear in greater quantity in the urine sample collected during the higher rate of flow.

Our observation that in 3 of 5 patients a greater quantity of creatinine was excreted during episodes of higher heart rates, therefore, does not prove that glomerular filtration was greater at higher heart rates. It might as well be explained by a dead space effect. The following numerical example gives an impression of magnitude of the effect. Given equal sampling periods with urine flows alternating between 162 and $351 \mathrm{ml}$. (mean values of 5 patients) and assuming complete mixing, it can be calculated that a dead space of $27 \mathrm{ml}$. is sufficient to explain the observed mean difference in creatinine excretion of 187 and $215 \mathrm{mg}$. at low and high heart rates, respectively.

The differences in excretion of sodium and chlor- ide cannot be ascribed to a dead space effect, since the concentration of these solutes does not vary inversely with flow. Potassium takes up an intermediate position. Potassium concentration was lower at higher heart rates in 4 patients, but the total quantity excreted was increased 30 to 76 per cent at the higher heart rates. This difference is greater than the corresponding difference in total quantity of creatinine excreted. It seems justified, therefore, to conclude from our urine samples that the excretion of potassium as well as sodium and chloride at the renal level is increased during higher heart rates.

These results confirm preliminary observations in a single patient (Dekker et al., 1963). They are at variance with the observations of Humphries et al. (1967) who found indications for a decrease in sodium excretion in patients with total heart block after pacing was started. These authors, however, were careful to point out that their patients were not maintained on a constant sodium intake and that 


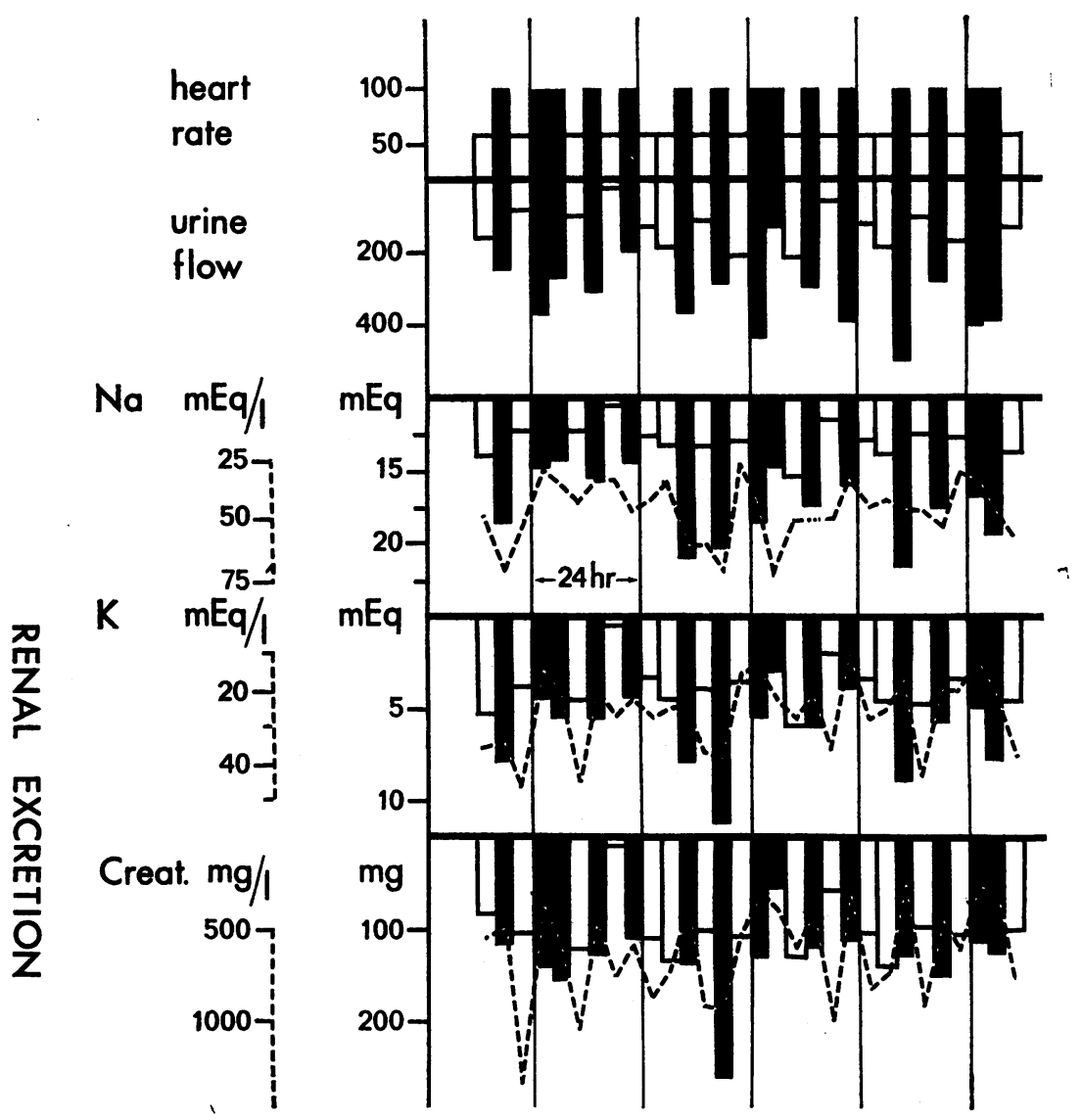

FIG. 4.- Heart rate and renal excretion of sodium, potassium, and creatinine in patient D. (See legend to Fig. 1.)

they were preloaded with water so that no firm conclusions could be drawn.

The mechanism by which heart rate affects renal excretion requires further elucidation. There are at present to our knowledge no methods available which enable us to ascribe with certainty variations in mineral excretion to either changes in glomerular filtration or tubular reabsorption (Wesson, 1957). This study was limited to the over-all behaviour of the kidney in handling minerals and urine flow. Even then the interesting question remains how the information about the changing heart rate reaches the kidney.

We and others (Benchimol, Li, and Dimond, 1964; Escher et al., 1964; Samet et al., 1964; Segel et al., 1964; Bevegård et al., 1967) found only a moderate increase in cardiac output when the paced rate was increased from 50 to 100 a minute in patients at rest. Moreover, if the heart rate is doubled by exercise in a normal subject, cardiac output will increase almost linearly with heart rate (Rushmer, 1959), whereas excretion of water and electrolytes will decrease (Wesson, 1957). Retention of extracellular fluid at low heart rates and reduction of the amount of extracellular fluid at higher heart rates may be part of a homeostatic mechanism which serves to keep cardiac output constantly adjusted to the metabolic state of the body (Borst, 1948; Ross, Linhart, and Braunwald, 1965; Bevegård et al., 1967; Guyton, 1967). It would thus be a mechanism similar to that which in the resting subject reduces stroke volume at an increase of paced rate. Cardiac output may conceivably but not necessarily convey the pertinent information to the kidney.

\section{SUMMARY}

The influence of heart rate on urine flow and excretion of minerals and creatinine was studied in patients with total heart block. 


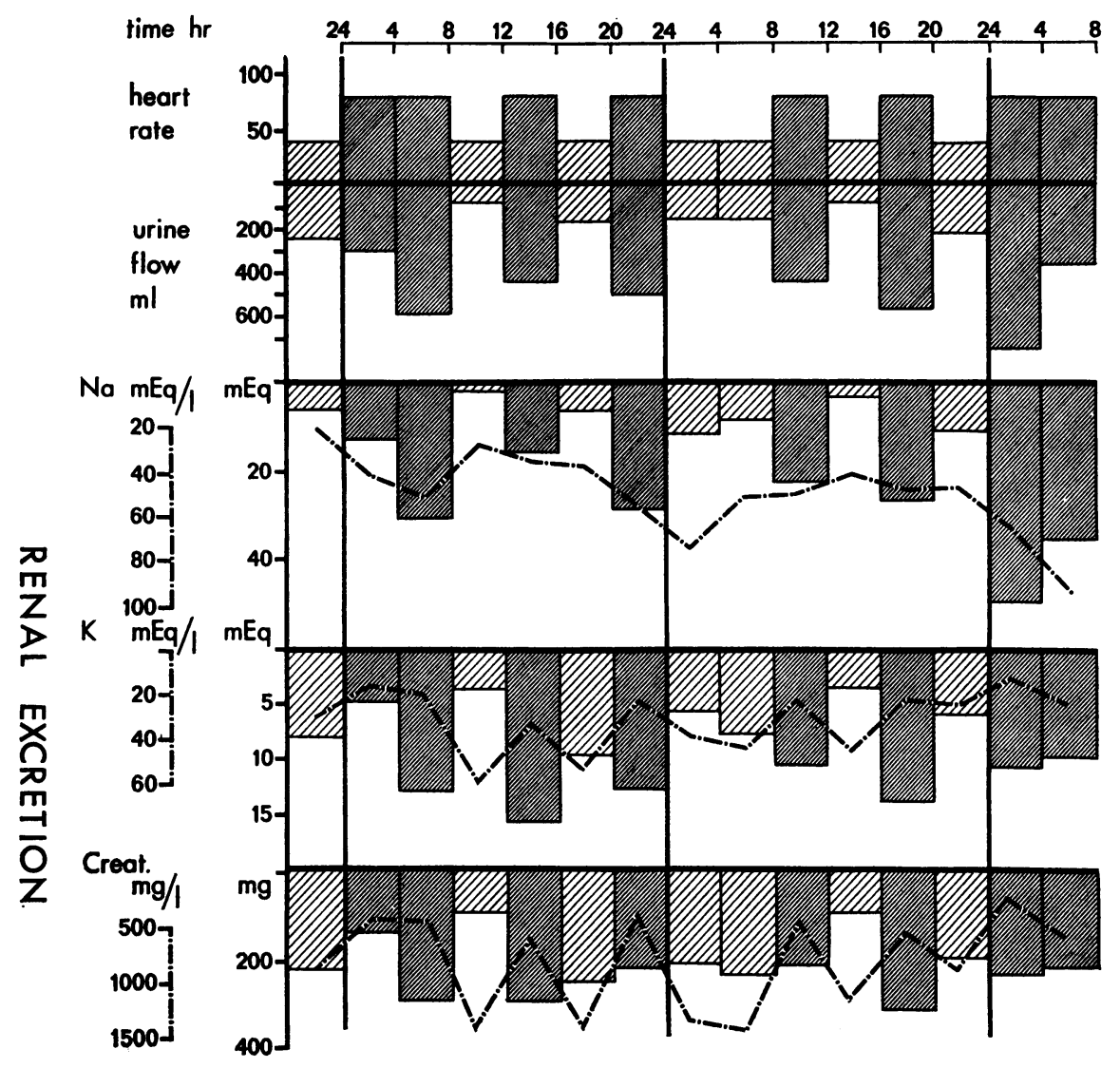

Fig. 5.-Heart rate and excretion data in patient E. (See legends to Fig. 1 and 4.)

The patients were maintained on a constant diet divided into 6 equal portions per 24 hours. Urine was collected in 4-hour periods. The heart rate was changed between 40 to 50 and 80 to 100 a minute between these 4-hour periods.

Urine flow and total amounts of sodium and chloride were considerably greater at the higher heart rates.

There was only a small increase in the total amount of creatinine collected during the higher heart rate.

The excretion of potassium showed a pattern intermediate between those of sodium chloride and creatinine.

The author wishes to thank Professor Dr. D. Durrer for his support and criticism, Dr. A. F. Willebrands, Dr. C. Baas, and their co-workers for the chemical determinations, and Ir. J. Oosting for his help with the statistical problems.

\section{REFERENCES}

Benchimol, A., Li, Y., and Dimond, E. G. (1964). Cardiovascular dynamics in complete heart block at various heart rates. Effect of exercise at a fixed heart rate. Circulation, 30, 542.

Bevegård, S., Jonsson, B., Karlöff, I., Lagergren, H., and Sowton, E. (1967). Effect of changes in ventricular rate on cardiac output and central pressures at rest and during exercise in patients with artificial pacemakers. Cardiovasc. Res., 1, 21.

Bojesen, E. (1954). The transport of urine in the upper urinary tract. Acta physiol. scand., 32, 39.

Borst, J. G. G. (1948). The maintenance of an adequate cardiac output by the regulation of the urinary excretion of water and sodium chloride; an essential factor in the genesis of oedema. Acta med. scand., 130, Suppl. 207.

Dekker, E., Meerschwam, I. S., Büller, J., and Pelser, H. E. (1963). The influence of electronically induced heart rate on the excretion of minerals and water in a patient with total heart block. Israel med. F., 22, 365.

DeSanctis, R. W. (1963). Short-term use of intravenous electrode in heart block. F. Amer. med. Ass., 184, 544. 
Escher, D. J. W., Schwedel, J. B., Schwartz, L. S., and Solomon, N. (1964). Transvenous electrical stimulation of the heart-II. Ann. N.Y. Acad. Sci., 111, 981.

Friedberg, C. K., Donoso, E., Stein, W. G., Kahn, M., and Litwak, R. (1965). The role of bradycardia in the retention of sodium and water in complete heart block with and without heart failure in human beings. Amer. Heart F., 69, 293.

Gorter, E., and de Graaff, W. C. (1955). Klinische Diagnostiek, 7th ed., Vol. 1, p. 440. Stenfert Kroese N.V., Leiden.

Guyton, A. C. (1967). Regulation of cardiac output. New Engl. f. Med., 227, 805.

Humphries, J. O., Hinman, E. J., Bernstein, L., and Walker, W. G. (1967). Effect of artificial pacing of the heart on cardiac and renal function. Circulation, 36, 717 .

Mann, H. B., and Whitney, D. R. (1947). On a test of whether one of two random variables is stochastically larger than the other. Ann. math. Statist., 18, 50.

Müller, O. F., and Bellet, S. (1961). Treatment of intractable heart failure in the presence of complete atrioventricular heart block by the use of the internal cardiac pacemaker. Report of two cases. New Engl. f. Med., 265, 768.

Ross, J., Jr., Linhart, J. W., and Braunwald, E. (1965). Effects of changing heart rate in man by electrical stimulation of the right atrium. Studies at rest, during exercise, and with isoproterenol. Circulation, 32, 549.

Rushmer, R. F. (1959). Constancy of stroke volume in ventricular responses to exertion. Amer. F. Physiol., 196, 745.

Samet, P., Bernstein, W. H., Medow, A., and Nathan, D. A. (1964). Effect of alterations in ventricular rate on cardiac output in complete heart block. Amer. $\mathcal{F}$. Cardiol., 14, 477.

Schales, O. (1953). Chloride. In Standard Methods of Clinical Chemistry, Vol. 1, p. 37. Ed. by M. Reiner. Academic Press, New York.

Scholander, P. F. (1947). Analyzer for accurate estimation of respiratory gases in one-half cubic centimeter samples. f. biol. Chem., 167, 235.

Schüller, H., Tryding, N., and Westling, H. (1964). Die Nierenfunktion bei totalem AV-Block vor und nach Pacemakerbehandlung. Thoraxchirurgie, 12, 189.

Segel, N., Hudson, W. A., Harris, P., and Bishop, J. M. (1964). The circulatory effects of electrically induced changes in ventricular rate at rest and during exercise in complete heart block. $\mathcal{F}$. clin. Invest., 43, 1541.

Wesson, L. G. (1957). Glomerular and tubular factors in the renal excretion of sodium chloride. Medicine (Baltimore), 36, 281. 